\title{
Logistics in supply chains (Part 2)
}

\author{
Martin Grunow • Hans-Otto Günther • David Pisinger
}

Published online: 1 December 2011

(C) Springer Science+Business Media, LLC 2011

The logistics function in supply chains is concerned with the efficient coordination of all entities, activities and resources involved in moving a product or service from its origin to final customers. Beyond the control of material flows, logistics management seeks to integrate transportation and material handling with the flow of information and financial values in the supply chain in order to fulfil customer requests. Altogether, inbound and outbound logistics of a company along with external logistics services constitute a market value that ranks logistics clearly among the top business sectors in any industrialized economy.

Based on the tremendous importance of logistics in supply chains and the considerable research contributions that have been achieved from disciplines like Production and Operations Management, Industrial Engineering and Operations Research, the primary objective of this special issue is to examine research issues concerned with logistics management in supply chains. For the second part of the special issue four papers have been selected for publication after a thorough peerreview according to the standards of the FSM journal. The first part with the following papers has been published in Volume 22 (2010), Numbers 1-2, of FSM.

M. Grunow ( $\square)$

Production and Supply Chain Management, Technische Universität München, Arcisstrasse 21, 80333 Munich, Germany

e-mail: martin.grunow@tum.de

H.-O. Günther

Department of Production Management, TU Berlin, Straße des 17. Juni 135, 10623 Berlin, Germany e-mail: hans-otto.guenther@tu-berlin.de

D. Pisinger

DTU Management Engineering, Technical University of Denmark, Produktionstorvet 424,

2800 Kgs, Lyngby, Denmark

e-mail: pisinger@man.dtu.dk 
- W.J.M. Meuffels, H.A. Fleuren, F.C.A.M. Cruijssen und E.R. van Dam: Enriching the tactical network design of express service carriers with fleet scheduling characteristics

- F.P. Deflorio, G. Perboli, R. Tadei: Freight distribution performance indicators for service quality planning in large transportation networks

- S.C.H. Leung, J. Zheng, D. Zhang, X. Zhou: Simulated annealing for the vehicle routing problem with two-dimensional loading constraints

- A.L. Kok, E.W. Hans, J.M.J. Schutten, W.H.M. Zijm: A dynamic programming heuristic for vehicle routing with time-dependent travel times and required breaks

- C.-F. Chien, J.-Z. Wu, Y.-D. Weng: Modeling order assignment for semiconductor assembly hierarchical outsourcing and developing the decision support system

\section{Papers in Part 2 of the special issue}

The first paper by R. Hammami, Y. Frein and A.B. Hadj-Alouane proposes a mixed integer programming model for a supplier selection problem in an international context taking issues like the buyers' locations, lead time uncertainty, delivery frequencies, and transportation modes into account. Computational experiments based on a realistic case study from the automotive industry are performed in order to illustrate the feasibility and the consistency of the model and to show how it can be used in many relevant managerial situations.

In their paper P. Farahani, M. Grunow and H.-O. Günther develop an integrative approach for short-term production and distribution planning of perishable food products. The production scheduling problem is solved through a novel mixedinteger linear optimization model while a large neighbourhood search heuristic is applied to determine the tours and schedules of the delivery vehicles. Numerical results show how the quality of foods can be improved by shortening the time interval between production and delivery.

The paper by $O$. Kulak, Y. Sahin and M.E. Taner investigates the problem of joint order batching and picker routing in single and multiple-cross-aisle warehouses. To solve these joint problems, the authors develop cluster-based tabu search algorithms. Numerical results reveal the superior performance of the proposed algorithms in terms of total route distance compared to benchmark solutions obtained from existing algorithms for both conventional warehouse layouts and multiple cross-aisle warehouse systems.

The problem of scheduling working and driving hours of team drivers in road freight transport is studied by A. Goel and L. Kok. Particularly, regulations introduced in the European Union which impose limits on the daily and weekly driving times of truck drivers are addressed. To solve this problem a depth-firstbreadth-second search method is developed which can find a feasible schedule in reasonable computational time. This method can also be extended to the general case in which standard driving time limits may be exceeded. 


\section{Concluding remarks}

This special issue has greatly benefited from the cooperation among the authors, reviewers, and editors. We would like to express our sincere thanks to the reviewers for their excellent and timely refereeing and the associate editor Prof. Herbert Kopfer, who supervised the review of the paper by P. Farahani et al. Last, but not least, we thank all authors for their contributions which made this special issue possible. 